\title{
Knowledge and Opinions of Saudi Dentists Regarding Dental Treatment of Patients Undergoing Bisphosphonates
}

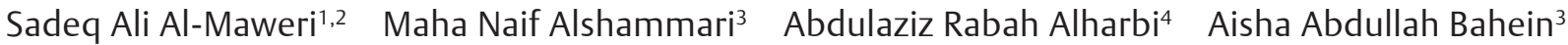 \\ Mohammed Nasser Alhajj ${ }^{5}$ Hashem Motahir Al-Shamiri, ${ }^{6, \bullet}$ Ahmed Wallan Alahmary ${ }^{6}$ \\ Mazen Doumani ${ }^{7}$
}

${ }^{1}$ Department of Oral Medicine and Diagnostic Sciences, AlFarabi

Address for correspondence Hashem Motahir Al-Shamiri, BDS, MSc, College for Dentistry and Nursing, Riyadh, Saudi Arabia Department of Oral and Maxillofacial Surgery, AlFarabi Colleges for

2Department of Oral Medicine, Faculty of Dentistry, Sana'a University, Sana'a, Yemen

${ }^{3}$ AlFarabi College for Dentistry and Nursing, Riyadh, Saudi Arabia

${ }^{4}$ College of Dentistry, Prince Sattam Bin Abdulaziz University,

Al Kharj, Saudi Arabia

${ }^{5}$ Department of Prosthodontics, Faculty of Dentistry, Thamar University, Dhamar, Yemen

6 Department of Oral and Maxillofacial Surgery, AlFarabi Colleges for Dentistry and Nursing, Riyadh, Saudi Arabia

${ }^{7}$ Department of Restorative Dental Sciences, Alfarabi Colleges for Dentistry and Nursing, Riyadh, Saudi Arabia Dentistry and Nursing, Riyadh 6847, 13226 Saudi Arabia (e-mail: Hashem_alshamiri@yahoo.com).

\section{Abstract \\ Keywords \\ - knowledge \\ - bisphosphonates \\ - osteonecrosis \\ - dental practitioners}

Objectives Bisphosphonates (BPs) are used for treatment of various benign and malignant medical conditions. Medications-related osteonecrosis of the jaws (MRONJ) is a very serious complication of prolonged therapy with BPs. This study aimed to assess the level of knowledge among dental professionals in Saudi Arabia regarding MRONJ. Materials and Methods This was a questionnaire-based, cross-sectional study. A self-administered questionnaire comprising close-ended questions about BPs and MRONJ was sent to a convenience sample of dentists in Saudi Arabia.

Statistical Analysis SPSS software was used for data analysis. Chi-square test was used to compare between the groups. The significance level was set at $p<0.05$.

Results A total of 607 dentists participated in this survey. Overall, the respondents showed insufficient level of knowledge regarding BPORNJ, with only $70 \%$ of the respondents had heard about BPORNJ, and less than $50 \%$ recognized the risk factors and clinical features of the disease. Additionally, while two-thirds of the respondents recognized the importance of taking BPs history, the majority did not know the correct treatment approach. Respondents with higher degrees (specialists) showed far better knowledge than general dentists.

Conclusion The knowledge regarding BPs therapy and its complications among Saudi dentists is unsatisfactory. Hence, interventions are highly required to improve dentists' knowledge regarding BPs and MRONJ.
DOI https://doi.org/

10.1055/s-0040-1701542

ISSN 1305-7456.
@2020 Dental Investigation Society
License terms

()(1) $\odot \circledast$ 


\section{Introduction}

Bisphosphonates (BPs) are a group of medications used to treat several bone lesions, including, but not limited to, osteoporosis, hypercalcemia, Paget's disease, multiple myeloma, and bone metastasis. ${ }^{1-3}$ The BPs have great affinity for bone tissues; they inhibit osteoclasts activity and thus reduce bone resorption and disrupt normal bone remodelling. ${ }^{1}$ BPs have been implicated in causing osteonecrosis of the jaws, a condition that was later called bisphosphonates-related osteonecrosis of the jaws (BRONJ).,.4 The first case of BRONJ was reported in 2003 by Marx, ${ }^{5}$ and since then numerous cases have been reported in the literature. ${ }^{6-10}$ BRONJ is a very serious condition that negatively impacts quality of life, producing a significant morbidity., ${ }^{3,411}$ It is characterized by an area of exposed bone that presents for more than 8 weeks with no history radiotherapy. ${ }^{11}$ As BRONJ cases can be associated with other antiresorptive medications (such as denosumab) and antiangiogenic therapies, the American Association of Maxillofacial Surgeons (AAOMS) in 2014 changed the nomenclature to medications-related osteonecrosis of the jaw (MRONJ). ${ }^{4}$ Although the exact etiopathogenesis of MRONJ is not fully elucidated, several risk factors have been suggested, including duration of BP therapy, route of BPs administration (e.g., the risk is significantly greater with intravenous BPs), dentoalveolar surgery, age of the patient, systemic diseases such as diabetes mellitus, and corticosteroid use, among others. ${ }^{3,4,12}$ Dentists can play a pivotal role in prevention of BRONJ/MRONJ through providing preventive care and prioritization of preventive treatment before the commencement of BPs. ${ }^{3,9,13,14}$ Hence, dentists and physicians must have adequate knowledge on BPs, its potential complications, and the appropriate treatment planning in patients at risk of MRONJ. ${ }^{14}$

The AAOMS published guidelines on staging and treatment strategies for patients receiving BPs.,4 The main purpose of these guidelines was to provide the clinicians a base knowledge on BPs, clinical features and risk factors of MRONJ/BRONJ, and most importantly, how to prevent and treat MRONJ/BRONJ. Unfortunately, despite these guidelines, several studies have shown very poor knowledge of dentists regarding treatment patients undergoing BPs therapy. ${ }^{2,13-16}$ Dentists can play a pivotal role in prevention of MRONJ in patients receiving BPs therapy. In Saudi Arabia, no information exists about the dentists' knowledge concerning BP therapy. Therefore, this study is aimed to assess the level of knowledge and opinions of dentists working in Saudi Arabia regarding dental treatment of patients receiving BP therapy.

\section{Materials and Methods}

This descriptive cross-sectional study was performed using a web-based structured questionnaire among dental professionals working in Saudi Arabia. The study was approved by the research and ethics committee, Al-Farabi colleges, Riyadh, and complied with the declared ethical principles of the World Medical Association Declaration of Helsinki (2002). A link of structured questionnaire was sent to a convenience sample of dental practitioners through emails or WhatsApp groups, and a cover letter explaining the purpose of the study and identified the research team was also included. The survey was sent to potential participants during November 2018 and February 2019. The sample size was calculated considering $95 \%$ confidence level, absolute precision of $5 \%$, and an expected level of knowledge of $50 \%$. The estimated sample size was 380 .

The self-administered questionnaire was adapted from previously validated questionnaires that had been used in similar studies. ${ }^{13-16}$ To ensure clarity and understandability, the questionnaire was pilot tested on 30 dentists. The questionnaire consisted of two main parts. The first part sought demographic and professional data including age, gender, graduation year, years of experience, specialization (general dentist or specialist), and type of working sector (public, private, and academic). The second section comprised closeended questions that assessed dentist's knowledge about BPs and MRONJ: the general knowledge about MRONJ, commercial names and therapeutic indications of BP, risk factors and clinical features of MRONJ, and knowledge regarding treatment guidelines for patients taking intravenous or oral BPs ( - Appendix A).

\section{Statistical Analysis}

IBM SPSS Version 21.0. software for Windows (IBM Corp., Armonk, New York) was used for data management and analysis. Descriptive statistics including frequencies and percentages were calculated. Chi-square test was used to compare between groups. The significance level was set at $p<0.05$.

\section{Results}

Out of the targeted 1,000 dentists, 607 completed the survey, giving a response rate of $60.7 \%(607 / 1,000)$. Most of the respondents were males (66.4\%), less than 40 years old $(84.2 \%)$, and had less than 5 years of clinical experience $(56.8 \%)$. Around half of the respondents (50.2\%) were general practitioners and $49.8 \%$ were specialists ( - Table $\mathbf{1}$ ).

- Table 2 presents results of the general knowledge about MRONJ and BP therapeutics. Around 71\% of the respondents were familiar with the term MRONJ, with no significant differences according to gender, qualifications, or years since graduation. Unfortunately, only one-third of the respondents reported to be familiar with the disease staging and treatment guidelines suggested by AAOMS, with a significant difference according to the qualification in favor of specialists $(p<0.01)$.

With regards to BP indications, the correct answers ranged between $33.4 \%$ and $57.5 \%$, with significant higher knowledge among specialists (average knowledge: 51\%) compared with general practitioners. Regarding commercial names of BPs, only one-third of the respondents were familiar with these medications, with significant better knowledge among specialist and those with long clinical experience. The total specialist knowledge is $36 \%$ (-Table 2). Around half of the respondents (49\%) gained the information about MRONJ from dental school/residency program and $10 \%$ from the internet (-Fig. 1). 
Table 1 General characteristics of the participants

\begin{tabular}{|c|c|c|}
\hline & $\mathrm{N}$ & $\%$ \\
\hline \multicolumn{3}{|l|}{ Age } \\
\hline$<30 y$ & 298 & 49.1 \\
\hline $30-39 y$ & 219 & 36.1 \\
\hline$\geq 40 y$ & 90 & 14.8 \\
\hline \multicolumn{3}{|l|}{ Gender } \\
\hline Male & 403 & 66.4 \\
\hline Female & 204 & 33.6 \\
\hline \multicolumn{3}{|l|}{ Graduation } \\
\hline $1-5 y$ & 308 & 50.7 \\
\hline $6-10 y$ & 157 & 25.9 \\
\hline$>10 y$ & 142 & 23.4 \\
\hline \multicolumn{3}{|l|}{ Experience } \\
\hline $1-5 y$ & 345 & 56.8 \\
\hline $6-10 y$ & 147 & 24.2 \\
\hline$>10 y$ & 115 & 18.9 \\
\hline \multicolumn{3}{|l|}{ Specialty } \\
\hline General practitioner & 305 & 50.2 \\
\hline Specialists & 302 & 48.2 \\
\hline \multicolumn{3}{|l|}{ Work } \\
\hline Academic sector & 113 & 18.6 \\
\hline Both public/private sectors & 70 & 11.5 \\
\hline Private sector & 210 & 34.6 \\
\hline Public sector & 214 & 35.3 \\
\hline
\end{tabular}

- Table 3 presents dentists' knowledge regarding risk factors and clinical features of MRONJ. Regarding risk factors for MRONJ, the correct answers ranged from 30.5 to $67.1 \%$. The most identified risk factors were type of BP therapy (67.1\%), dentoalveolar surgery (55.4\%), age of the patient (51.6\%), and route of drug administration (51.7\%). Similarly, the dentists' knowledge regarding clinical features of the disease was very low, ranging from $38.9 \%$ to $64.9 \%$. Specialist showed significantly better knowledge regarding the risk factors of MRONJ than general practitioners $(p<0.01)$. Additionally, specialists showed better knowledge regarding the clinical features of the disease, but with no significant differences except in one item. However, no significant association was observed between level of knowledge and gender and years since graduation.

- Table 4 presents dentists' responses to questions regarding dental treatment strategies in patients receiving BPs. Around two-thirds of the respondents believe that taking BPs history is important for all patients, and that all patients should be checked by a dentist before commencement of BP therapy. However, the majority did not have sufficient knowledge regarding the appropriate treatment strategies for patients undergoing BPs therapy, with only 25.7 to $51 \%$ knew the correct treatment strategy for each scenario. Generally, specialist showed significantly better knowledge in all items than general practitioners.

\section{Discussion}

To the best of our knowledge, this is the first study that assessed MRONJ knowledge among dental practitioners in Saudi Arabia. Overall, the results revealed a very alarming lack of knowledge on MRONJ among the surveyed dentists,

Table 2 General knowledge about BRONJ and indications/types of BP (\% of Yes answers)

\begin{tabular}{|c|c|c|c|c|c|c|c|c|c|c|c|}
\hline & \multirow[t]{2}{*}{ Total } & \multicolumn{3}{|c|}{ Gender } & \multicolumn{3}{|c|}{ Specialty } & \multicolumn{4}{|c|}{ Years since graduation } \\
\hline & & $M$ & $F$ & $p$-Value & GP & Specialist & $p$-Value & $\begin{array}{l}1-5 \\
\text { years }\end{array}$ & $\begin{array}{l}6-10 \\
\text { years }\end{array}$ & $\begin{array}{l}>10 \\
\text { Years }\end{array}$ & $p$-Value \\
\hline \multicolumn{12}{|l|}{ General knowledge } \\
\hline $\begin{array}{l}\text { Familiar with } \\
\text { BRONJ }\end{array}$ & 71 & 73.2 & 66.7 & 0.107 & 63.9 & 78.1 & 0.000 & 69.5 & 71.3 & 73.9 & 0.621 \\
\hline $\begin{array}{l}\text { Familiar with } \\
\text { staging and } \\
\text { guidelines by } \\
\text { AAOMS }\end{array}$ & 36.4 & 37.5 & 34.3 & 0.476 & 26.2 & 46.7 & 0.000 & 30.8 & 45.2 & 38.7 & 0.008 \\
\hline \multicolumn{12}{|l|}{ Uses of BP** } \\
\hline $\begin{array}{l}\text { Bone } \\
\text { metastases }\end{array}$ & 52.2 & 51.9 & 52.9 & 0.758 & 46.6 & 57.9 & 0.019 & 49.7 & 53.5 & 56.3 & 0.436 \\
\hline $\begin{array}{l}\text { Multiple } \\
\text { myeloma }\end{array}$ & 35.3 & 34.5 & 36.8 & 0.367 & 29.5 & 41.1 & 0.001 & 31.2 & 37.6 & 41.5 & 0.241 \\
\hline $\begin{array}{l}\text { Hypercalcemia } \\
\text { of malignancy }\end{array}$ & 33.4 & 33.3 & 33.8 & 0.907 & 28.9 & 38.1 & 0.033 & 28.6 & 38.9 & 38.0 & 0.127 \\
\hline $\begin{array}{l}\text { Osteopenia and } \\
\text { Osteoporosis }\end{array}$ & 57.5 & 57.6 & 57.4 & 0.996 & 48.9 & 66.2 & 0.000 & 54.5 & 59.2 & 62.0 & 0.221 \\
\hline $\begin{array}{l}\text { Paget's disease } \\
\text { of bone }\end{array}$ & 45.8 & 44.4 & 48.5 & 0.579 & 40.0 & 51.7 & 0.002 & 42.9 & 47.8 & 50.0 & 0.414 \\
\hline
\end{tabular}


Table 2 (continued)

\begin{tabular}{|l|l|l|l|l|l|l|l|l|l|l|l|l|}
\hline & Total & \multicolumn{3}{|c|}{ Gender } & \multicolumn{3}{c|}{ Specialty } & \multicolumn{3}{c|}{ Years since graduation } \\
\cline { 3 - 12 } & & $\mathbf{M}$ & $\mathrm{F}$ & $\boldsymbol{p}$-Value & GP & Specialist & $\boldsymbol{p}$-Value & $\begin{array}{l}1-5 \\
\text { years }\end{array}$ & $\begin{array}{l}6-10 \\
\text { years }\end{array}$ & $\begin{array}{l}>10 \\
\text { Years }\end{array}$ & \\
\hline Types of BP** & & & & & & & & & & & \\
\hline $\begin{array}{l}\text { Alendronate } \\
\text { (Fosamax) }\end{array}$ & 35.1 & 36.5 & 32.4 & 0.584 & 23.9 & 46.4 & 0.000 & 28.2 & 38.9 & 45.8 & 0.000 \\
\hline $\begin{array}{l}\text { Risendronate } \\
\text { (Actonel) }\end{array}$ & 23.4 & 25.8 & 18.6 & 0.122 & 17.7 & 29.1 & 0.003 & 16.6 & 29.9 & 31.0 & 0.001 \\
\hline $\begin{array}{l}\text { Ibandronate } \\
\text { (Boniva) }\end{array}$ & 24.5 & 27.0 & 19.6 & 0.057 & 20.3 & 28.8 & 0.012 & 20.1 & 29.9 & 28.2 & 0.058 \\
\hline $\begin{array}{l}\text { Zolendronate } \\
\text { (Zometa) }\end{array}$ & 30.3 & 33.5 & 24.0 & 0.034 & 21.0 & 39.7 & 0.000 & 23.7 & 36.9 & 37.3 & 0.001 \\
\hline
\end{tabular}

Abbreviations: BP, bisphosphonate; BRONJ, bisphosphonate-related osteonecrosis of the jaw; F, female; GP, general practitioner; M, male. ** "Yes" is the correct answer for all items.

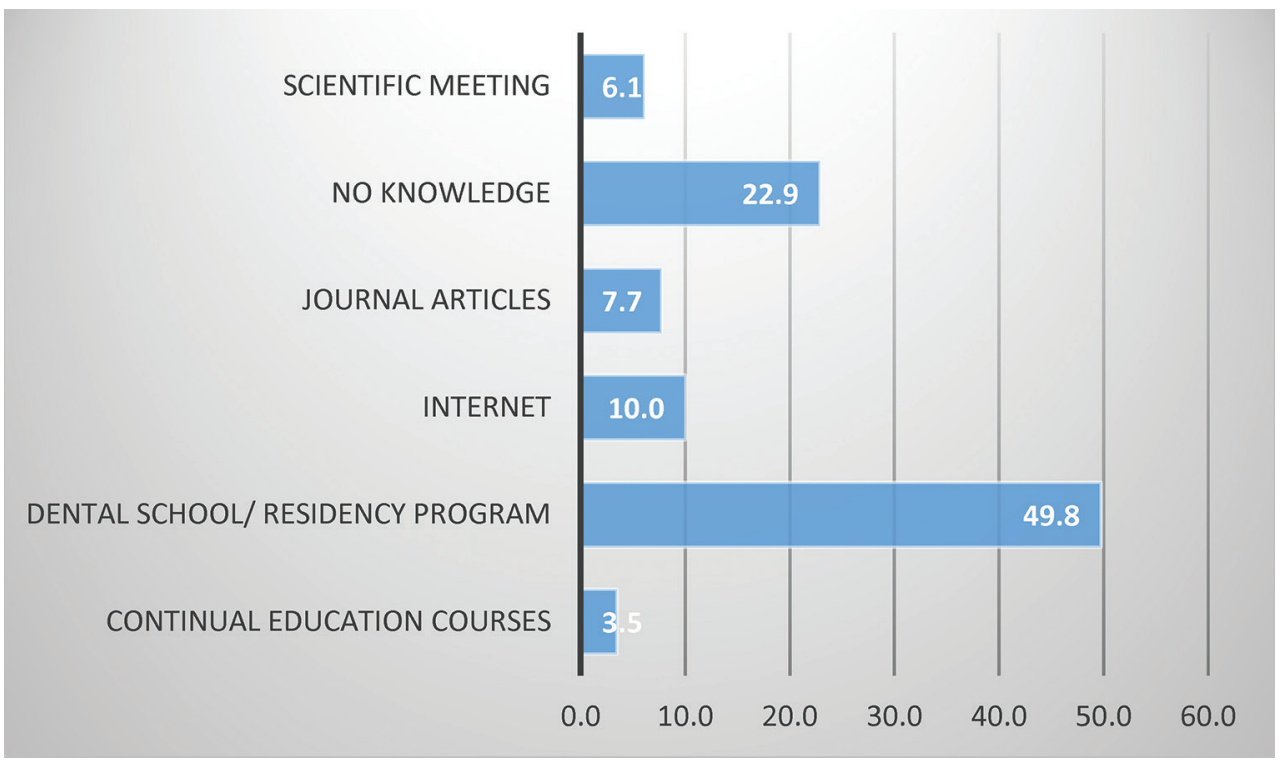

Fig. 1 Source of information regarding MRONJ.

with a significant better knowledge among respondents with higher degrees (specialists) compared with general practitioners. However, the results of the present study should be interpreted with caution given the methodological shortcomings explained at the end of this section.

The main result of the present study was the evident poor level of knowledge about MRONJ and BPs, with only $70 \%$ of dentists have heard about the disease, less than half of the respondents knew about the risk factors and clinical features of MRONJ, and the majority could not recognize the commercial names of BPs. Our findings are in line with most of previous similar studies in different countries, which reported very poor knowledge on MRONJ and BPs among dentists. 2,13-16 This can be attributed to the insufficient exposure of dentists to these topics during undergraduate and postgraduate education. ${ }^{17}$ Additionally, lack of periodic continuing educational courses such as attending workshops and seminars is another contributing factor.
MRONJ adversely affects the quality of life, producing significant morbidity in afflicted patients. Therefore, dentists should have adequate knowledge about MRONJ, especially regarding the appropriate treatment strategies in patients undergoing BPs therapy. Luckily, the AAOMS have set very clear guidelines regarding MRONJ staging and treatment strategies of patients at risk of this debilitating disease. However, despite the existence of these guidelines, several studies have shown that majority of dentists were not aware as how to carry out invasive treatments (such as tooth extraction) in patients undergoing BPs therapy. ${ }^{2,13,16}$ Our results are not exception as most of dentists in the present study showed very poor knowledge in this regard. While two-thirds of respondents acknowledged the importance of taking BP history, the majority were not aware of the treatment strategies of patients at risk of MRONJ. For example, only $20 \%$ of dentists knew that no invasive dental treatment should be done in patients receiving IV BP. These results are indeed a reason 
Table 3 Knowledge regarding risk factors and clinical features of MRON] (\% of correct answers [Yes answers])

\begin{tabular}{|c|c|c|c|c|c|c|c|c|c|c|c|}
\hline \multirow[t]{2}{*}{ Items } & \multirow[t]{2}{*}{ Total } & \multicolumn{3}{|c|}{ Gender } & \multicolumn{3}{|c|}{ Specialty } & \multicolumn{4}{|c|}{ Years since graduation } \\
\hline & & M & $F$ & $p$-Value & GP & Specialist & $p$-Value & $1-5 y$ & $6-10 y$ & $>10 y$ & p-Value \\
\hline \multicolumn{12}{|l|}{ Risk factors } \\
\hline Type of BP therapy & 67.1 & 66.7 & 67.6 & 0.722 & 61.0 & 73.2 & 0.001 & 64.6 & 68.8 & 70.4 & 0.683 \\
\hline Route of administration & 51.7 & 53.6 & 48.0 & 0.399 & 40.3 & 63.2 & 0.000 & 46.8 & 55.4 & 58.5 & 0.103 \\
\hline Age of the patient & 51.6 & 51.4 & 52.0 & 0.906 & 49.2 & 54.0 & 0.026 & 52.6 & 51.6 & 49.3 & 0.884 \\
\hline Gender & 30.5 & 29.5 & 32.4 & 0.576 & 31.1 & 29.8 & 0.199 & 32.1 & 24.2 & 33.8 & 0.394 \\
\hline Tobacco use & 40.4 & 38.7 & 43.6 & 0.425 & 42.0 & 38.7 & 0.444 & 39.3 & 36.9 & 46.5 & 0.366 \\
\hline Diabetes mellitus & 47.8 & 47.4 & 48.5 & 0.904 & 45.2 & 50.3 & 0.001 & 44.8 & 50.3 & 51.4 & 0.392 \\
\hline Use of steroid & 48.8 & 48.9 & 48.5 & 0.852 & 43.3 & 54.3 & 0.002 & 42.9 & 53.5 & 56.3 & 0.018 \\
\hline Type of Bisphosphonate & 47.1 & 49.1 & 43.1 & 0.232 & 40.0 & 54.3 & 0.000 & 43.5 & 49.7 & 52.1 & 0.333 \\
\hline Genetic factors & 33.9 & 33.0 & 35.8 & 0.674 & 29.5 & 38.4 & 0.068 & 30.8 & 37.6 & 36.6 & 0.096 \\
\hline Denture wearing & 32.5 & 32.3 & 32.8 & 0.191 & 29.2 & 35.8 & 0.029 & 26.0 & 40.1 & 38.0 & 0.005 \\
\hline Dentoalveolar surgery & 55.4 & 56.8 & 52.5 & 0.296 & 46.2 & 64.6 & 0.000 & 51.6 & 56.7 & 62.0 & 0.174 \\
\hline $\begin{array}{l}\text { Local anatomical } \\
\text { factors }\end{array}$ & 47.4 & 46.9 & 48.5 & 0.293 & 39.0 & 56.0 & 0.000 & 44.2 & 49.7 & 52.1 & 0.355 \\
\hline Presence of oral disease & 49.8 & 48.6 & 52.0 & 0.233 & 46.2 & 53.3 & 0.004 & 46.8 & 53.5 & 52.1 & 0.262 \\
\hline \multicolumn{12}{|l|}{ Clinical features } \\
\hline Pain & 61.9 & 59.6 & 66.7 & 0.083 & 62.0 & 61.9 & 0.442 & 61.7 & 63.1 & 63.1 & 0.213 \\
\hline Purulent discharge & 47.0 & 47.4 & 46.1 & 0.088 & 42.6 & 51.3 & 0.087 & 41.6 & 53.5 & 51.4 & 0.067 \\
\hline Exposed bone & 64.9 & 63.5 & 67.6 & 0.563 & 61.0 & 68.9 & 0.100 & 63.6 & 66.2 & 66.2 & 0.765 \\
\hline Fistula & 38.9 & 39.0 & 38.7 & 0.812 & 34.4 & 43.4 & 0.077 & 34.1 & 43.9 & 43.7 & 0.149 \\
\hline Paraesthesia & 45.0 & 45.4 & 44.1 & 0.741 & 40.3 & 49.7 & 0.024 & 41.9 & 47.1 & 49.3 & 0.564 \\
\hline Pathologic fracture & 57.2 & 59.1 & 53.4 & 0.176 & 52.5 & 61.9 & 0.059 & 56.2 & 57.3 & 59.2 & 0.895 \\
\hline
\end{tabular}

Abbreviations: BP, bisphosphonate; $\mathrm{F}$, female; GP, general practitioner; $\mathrm{M}$, male.

Note: "Yes" is the correct answer for all questions.

Table 4 Knowledge regarding dental therapy/preventive strategies in patients undergoing BP treatment (\% of the correct answer)

\begin{tabular}{|c|c|c|c|c|c|c|c|c|}
\hline & \multirow[t]{2}{*}{ Total } & \multicolumn{3}{|c|}{ Specialty } & \multicolumn{4}{|c|}{ Years since graduation } \\
\hline & & GP & Specialist & $P$-Value & $\begin{array}{l}1-5 \\
\text { years }\end{array}$ & $\begin{array}{l}6-10 \\
\text { years }\end{array}$ & $\begin{array}{l}>10 \\
\text { years }\end{array}$ & $P$-Value \\
\hline Taking BP history is important? (correct answer: Yes) & & 63.0 & 77.8 & 0.000 & 68.2 & 68.8 & 76.8 & 0.348 \\
\hline $\begin{array}{l}\text { Patients to be checked by a dentist before BP treatment? } \\
\text { (correct answer: Yes) }\end{array}$ & 71.7 & 63.6 & 79.8 & 0.000 & 68.5 & 75.2 & 74.6 & 0.451 \\
\hline $\begin{array}{l}\text { Invasive dental treatment during IV BP therapy? } \\
\text { (correct answer: No) }\end{array}$ & 51.6 & 43.6 & 59.6 & 0.000 & 49 & 53.5 & 54.9 & 0.393 \\
\hline $\begin{array}{l}\text { Dental treatment in patients with oral BP therapy for } \\
<4 \text { years without risk factors? (correct answer: Yes) }\end{array}$ & 40.5 & 30.5 & 50.7 & 0.000 & 32.1 & 43.3 & 55.6 & 0.000 \\
\hline $\begin{array}{l}\text { Invasive dental treatment during oral BP therapy for }<4 \text { years } \\
\text { with risk factors? (correct answer: No) }\end{array}$ & 34.6 & 29.5 & 39.7 & 0.000 & 34.7 & 35 & 33.8 & 0.137 \\
\hline $\begin{array}{l}\text { Invasive dental treatment during oral BP therapy for more } \\
\text { than } 4 \text { years? (correct answer: No) }\end{array}$ & 25.7 & 20.3 & 31.1 & 0.001 & 24.7 & 24.2 & 29.6 & 0.053 \\
\hline
\end{tabular}

Abbreviations: BP, bisphosphonate; F, female; GP, general practitioner; M, male.

for concern and necessitate an immediate action to improve dentists' awareness about MRONJ and the importance of following the established guidelines for treatment of people at the risk MRONJ. Conducting periodic continuing education courses and workshops related to MRONJ is the answer to address this evident gap in the knowledge about MRONJ and to implement these guidelines.

The other important finding was the noticeable better knowledge among specialists compared with general practitioners. These results are not surprising as specialists had better exposure to the topic during postgraduate studies, which may explain their better knowledge. Additionally, specialists usually are more interested in attending conferences and scientific activities. However, despite that, the knowledge of specialists in our study is still below average, and hence more work should be done to promote their knowledge regarding diagnosis and prevention of MRONJ.

As stated above, this is the first survey that assessed dentists' knowledge concerning MRONJ in Saudi Arabia. However, the survey has some limitations that should be 
acknowledged. First, low response rate is an obvious limitation of the study. Second, this study used a convenience sample of dentists and, thus, generalization of the results is limited. Third, this is a self-reported survey and thus the responses might not have reflected the real knowledge of dentists. However, despite these limitations, we believe that this study has shed some light and provided valuable baseline information on the level of MRONJ knowledge among dental professionals nationwide.

In summary, this study, similar to previous studies in other countries, revealed very poor knowledge of MRONJ among dentists practicing in Saudi Arabia. Such alarming results necessitate an immediate action to improve dentists' awareness and knowledge about MRONJ treatment and prevention. Periodic continuing courses about how treat and prevent MRONJ in patients receiving BPs therapy are highly recommended.

\section{Conflict of Interest}

None declared.

\section{References}

1 Reyes C, Hitz M, Prieto-Alhambra D, Abrahamsen B. Risks and benefits of bisphosphonate therapies. J Cell Biochem 2016;117(1):20-28

2 Vinitzky-Brener I, Ibáñez-Mancera N-G, Aguilar-Rojas A-M, Álvarez-Jardón A-P. Knowledge of bisphosphonate-related osteonecrosis of the Jawsamong Mexican dentists. Med Oral Patol Oral Cir Bucal 2017;22(1):e84-e87

3 Ruggiero SL, Dodson TB, Fantasia J, et al; American Association of Oral and Maxillofacial Surgeons. American Association of Oral and Maxillofacial Surgeons position paper on medication-related osteonecrosis of the jaw-2014 update. J Oral Maxillofac Surg 2014;72(10):1938-1956

4 Ruggiero SL, Dodson TB, Assael LA, Landesberg R, Marx RE, Mehrotra B; American Association of Oral and Maxillofacial Surgeons. American Association of Oral and Maxillofacial Surgeons position paper on bisphosphonate-related osteonecrosis of the jaws-2009 update. J Oral Maxillofac Surg 2009;67(5, Suppl):2-12

5 Marx RE. Pamidronate (Aredia) and zoledronate (Zometa) induced avascular necrosis of the jaws: a growing epidemic. J Oral Maxillofac Surg 2003;61(9):1115-1117
6 Levin L, Laviv A, Schwartz-Arad D. Denture-related osteonecrosis of the maxilla associated with oral bisphosphonate treatment. J Am Dent Assoc 2007;138(9):1218-1220

7 Lee JJ, Cheng SJ, Jeng JH, Chiang CP, Lau HP, Kok SH. Successful treatment of advanced bisphosphonate-related osteonecrosis of the mandible with adjunctive teriparatide therapy. Head Neck 2011;33(9):1366-1371

8 Bedogni A, Bettini G, Totola A, Saia G, Nocini PF. Oral bisphosphonate-associated osteonecrosis of the jaw after implant surgery: a case report and literature review. J Oral Maxillofac Surg 2010;68(7):1662-1666

9 Gil IG, Ponte BM, Mateo ST, García JJ. Treatment of bisphosphonate-related osteonecrosis of the jaw with plasma rich in growth factors after dental implant surgery: a case report. J Oral Implantol 2019;45(4):289-296

10 Suzuki N, Oguchi H, Yamauchi Y, Karube Y, Suzuki Y, Hosoya N. A case of tooth fracture occurred upon medicating bisphosphonate for an elderly person: preservation therapy and responses for Stage 0 of bisphosphonate-related osteonecrosis of jaw. Eur J Dent 2017;11(2):258-263

11 Thumbigere-Math V, Sabino MC, Gopalakrishnan R, et al. Bisphosphonate-related osteonecrosis of the jaw: clinical features, risk factors, management, and treatment outcomes of 26 patients. J Oral Maxillofac Surg 2009;67(9):1904-1913

12 Awad ME, Sun C, Jernigan J, Elsalanty M. Serum C-terminal cross-linking telopeptide level as a predictive biomarker of osteonecrosis after dentoalveolar surgery in patients receiving bisphosphonate therapy: systematic review and meta-analysis. J Am Dent Assoc 2019;150(8):664-675.e8

13 Alhussain A, Peel S, Dempster L, Clokie C, Azarpazhooh A. Knowledge, practices, and opinions of Ontario dentists when treating patients receiving bisphosphonates. J Oral Maxillofac Surg 2015;73(6):1095-1105

14 de Lima PB, Brasil VLM, de Castro JFL, et al. Knowledge and attitudes of Brazilian dental students and dentists regarding bisphosphonate-related osteonecrosis of the jaw. Support Care Cancer 2015;23(12):3421-3426

15 López-Jornet $\mathrm{P}$, Camacho-Alonso F, Molina-Miñano F, Gomez-Garcia F. Bisphosphonate-associated osteonecrosis of the jaw. Knowledge and attitudes of dentists and dental students: a preliminary study. J Eval Clin Pract 2010;16(5):878-882

16 Yoo JY, Park YD, Kwon YD, Kim DY, Ohe JY. Survey of Korean dentists on the awareness on bisphosphonate-related osteonecrosis of the jaws. J Investig Clin Dent 2010;1(2):90-95

17 Rosella D, Papi P, Pompa G, Capogreco M, De Angelis F, Di Carlo S. Dental students' knowledge of medication-related osteonecrosis of the jaw. Eur J Dent 2017;11(4):461-468 
Appendix A Survey Title: Knowledge and Opinions of Saudi Dentists Regarding Dental Treatment of Patients Undergoing Bisphosphonates

\section{Domain 1: Demographic Data}

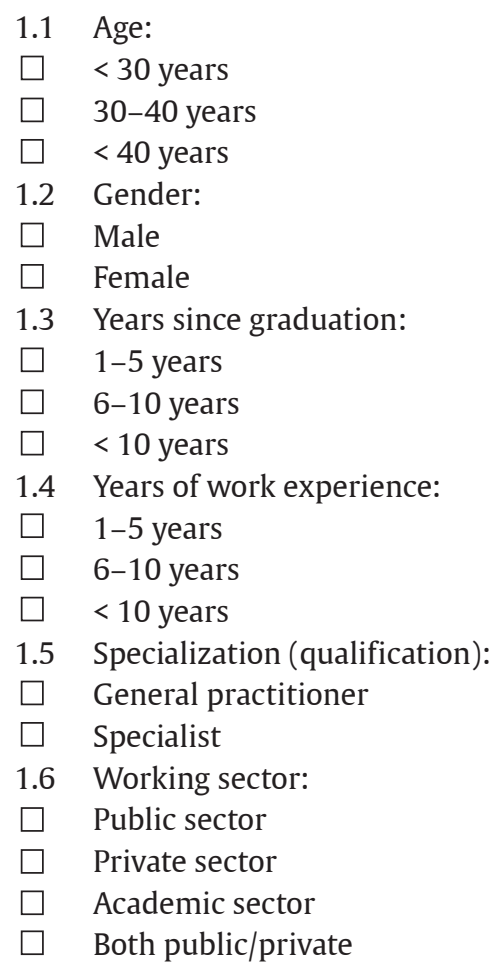

1.4 Years of work experience:

1-5 years

$6-10$ years

$<10$ years

1.5 Specialization (qualification):

$\square \quad$ General practitioner

Specialist

1.6 Working sector:

$\square \quad$ Public sector

Private sector

Academic sector

Both public/private

\section{Domain 2: General knowledge}

2.1 Are you familiar with the term bisphosphonates-related osteonecrosis of the jaw (BRONJ)?

$\square \quad$ Yes

No

2.2 From where you learnt about BRONJ for the first time?

No knowledge

Dental school/residency program

Internet

Scientific meeting

Journal articles

Continual education courses

2.3 During dental history taking, do you think it is important to ask if the patient is using bisphosphonates medication? Yes

No

Don't know

2.4 Are you familiar with bisphosphonates-related osteonecrosis staging guidelines and treatment strategies suggested by American Association of Oral and Maxillofacial Surgeons (AAOMS)?

$\square \quad$ Yes

$\square \quad$ No 
Appendix A (continued)

\subsection{Indications of Bisphosphonates?}

2.5.1 Bone metastases

$\square$ Yes

2.5.2 Multiple myeloma

2.5.3 Hypercalcemia of malignancy

2.5.4 Osteopenia and osteoporosis

2.5.5 Paget's disease of bone

2.6 Names of bisphosphonate medications that you are aware of?

2.6.1 Alendronate (Fosamax)

2.6.2 Risendronate (Actonel)

2.6.3 Ibandronate (Boniva)

2.6.4 Zolendronate (Zometa) $\square$ Yes

$\square$ Yes

$\square$ Yes

$\square$ Yes

$\square$ Yes

$\square$ Yes

$\square$ Yes

$\square$ Yes $\square$ No

$\square$ No

$\square$ No

$\square$ No

$\square$ No

$\square$ No

$\square$ No

$\square$ No

$\square$ No
Don't know

Don't know

Don't know

Don't know

Don't know

Don't know

Don't know

Don't know

Don't know

\section{Domain 3: Risk factors}

\subsection{Risk factors related to development of bisphosphonates-related osteonecrosis of the jaw}

3.1.1 Duration of bisphosphonate therapy

3.1.2 Route of administration (oral/IV)

3.1.3 Age of the patient

3.1.4 Gender

3.1.5 Tobacco use

3.1.6 Diabetes mellitus

3.1.7 Use of steroid

3.1.8 Type of bisphosphonate medications

3.1.9 Genetic factors

3.1.10 Denture wearing

3.1.11 Dentoalveolar surgery

3.1.12 Local anatomical factors (for example mandible versus maxilla)

3.1.13 Presence of oral disease $\square$ Yes $\quad \square$ No

$\square$ Yes

$\square$ Yes

$\square$ Yes

$\square$ Yes

$\square$ Yes

$\square$ Yes

$\square$ Yes

$\square$ Yes

$\square$ Yes

$\square$ Yes

$\square$ Yes

$\square$ Yes $\square$ No

$\square$ No

$\square$ No

$\square$ No

$\square$ No

$\square$ No

$\square$ No

$\square$ No

$\square$ No

$\square$ No

$\square$ No

$\square$ No
Don't know

Don't know

Don't know

Don't know

Don't know

Don't know

Don't know

Don't know

Don't know

Don't know

Don't know

Don't know

Don't know

\section{Domain 4: Clinical features}

\subsection{Clinical features of bisphosphonates-related osteonecrosis of the jaw?}

4.1.1 Pain

4.1.2 Purulent discharge

4.1.3 Exposed bone

4.1.4 Fistula

4.1.5 Paraesthesia

4.1.6 Pathologic fracture $\square$ Yes

$\square$ Yes

$\square$ Yes

$\square$ Yes

$\square$ Yes

$\square$ Yes $\square$ No

$\square$ No

$\square$ No

$\square$ No

$\square$ No

$\square$ No
Don't know

Don't know

Don't know

Don't know

Don't know

Don't know

\section{Domain 5: Management and prevention strategies}

5.1 Do you think that patients should be checked by a dentist before starting intravenous bisphosphonates treatment?

$\square$ Yes

$\square$ No

Don't know

5.2 Can invasive dental treatment be given to the patient during an intravenous bisphosphonate drug therapy?

Don't know

5.3 Can invasive dental treatment be given to a patient using oral bisphosphonate for less than 4 years in the absence of risk factors?

Don't know

5.4 Can invasive dental treatment be given to patient using oral bisphosphonates for less than 4 years with risk factors?

Don't know

5.5 Can invasive dental treatment be given to patient using oral bisphosphonates for more than 4 years?

Yes

$\square$ No

Don't know 